\title{
O ensino dos jogos esportivos coletivos: as competências essenciais e a lógica do jogo em meio ao processo organizacional sistêmico
}

\author{
Alcides José Scaglia* \\ Riller Silva Reverdito** \\ Lucas Leonardo ${ }^{* * *}$ \\ Cristian Javier Ramirez Lizana ${ }^{* * * *}$
}

\begin{abstract}
Resumo: Neste artigo descritivo e propositivo temos como objetivo abordar o processo de ensino dos jogos esportivos coletivos, partindo do pressuposto que devem ser entendidos a partir da natureza ontológica do jogo, do processo organizacional e da lógica inerente aos jogos coletivos. Propomos o processo de ensino tendo por referência a concepção de competências essenciais, as quais emanam da interação entre as referências funcionais e estruturais, as quais regulam a lógica do jogo. Portanto, lançamos as bases para o desenvolvimento de uma metodologia pautada no jogo e dos parâmetros para a estruturação do currículo de formação baseado em competências.

Palavras chave: jogos esportivos coletivos, competências essenciais, lógica do jogo, processo organizacional sistêmico.
\end{abstract}

\section{JOGO ESPORTIVO COLETIVO É ANTES DE TUDO UM JOGO}

Precedendo o início das reflexões sobre quaisquer jogos esportivos coletivos, queremos salientar e destacar que, antes de tudo, devemos entendê-los enquanto jogo. E o fenômeno jogo dever ser compreendido na perspectiva sistêmica e complexa, em que seu

\footnotetext{
"Faculdade de Ciências Aplicadas, Universidade de Campinas, Campinas, SP, Brasil. E-mail: alcides.scaglia@fca.unicamp.br

"Faculdade de Educação Física, Universidade de Campinas, Campinas, SP, Brasil; Faculdade Adventista de Hortolândia, Universidade Adventista de São Paulo, Hortolândia, SP, Brasil. Email: rsreverdito@gmail.com

"'Colégio Objetivo de Campinas e Prefeitura Municipal de Campinas, Campinas, SP, Brasil. PMC/SME. E-mail: lucas.leo@gmail.com

"...Faculdade de Ciências Aplicadas Universidade de Campinas, Campinas, SP, Brasil. E-mail: crlizana1@gmail.com
} 
ambiente (contexto) decidirá o que é jogo ou não, evidenciando a predominância da subjetividade em detrimento da objetividade, caracterizando estado de jogo ${ }^{1}$ (SCAGLIA, 2005; 2011).

Percebê-los enquanto jogo é pré-requisito fundamental para a sustentação e construção de metodologias inovadoras em pedagogia do esporte, as quais se valem do jogo para a efetivação de processos coerentes de iniciação, especialização e aperfeiçoamento nos esportes coletivos.

Partindo do pressuposto que os jogos esportivos coletivos devem ser entendidos a partir da ontologia ${ }^{2}$ do jogo (LEONARDO; SCAGLIA; REVERDITO, 2009), e o principal aspecto que sustenta essa afirmação é sua natureza como atividade. A natureza do jogo como atividade se caracteriza pelo seu caráter livre, delimitada, regulamentada, incerta, improdutiva e fictícia (ALVES, 1987; CHATEAU, 1987; MARCELLINO, 1989; EIGEN; WINKLER, 1989; CAILLOIS, 1988, 1990; BROUGÈRE, 1998; HUIZINGA, 1999; FREIRE, 2002; KISHIMOTO, 2002; RETONDAR, 2007; GADAMER, 2002, 2007)3. É justamente a natureza do jogo como atividade, nesse caso os jogos esportivos coletivos, que irá garantir e sustentar o desejo do jogador de ao jogo se entregar (REVERDITO, 2011; SCAGLIA, 2011).

Mas nem tudo é jogo. As suas características se evidenciam estruturando a ação, ou seja, é o contexto (ambiente) que irá determinar o que é jogo e não-jogo (FREIRE, 2002; SCAGLIA,

\footnotetext{
'Estado de jogo: é a condição de concentração em que o jogador se encontra ao ser envolvido e se envolver com o jogo. É o estado de jogo que garante a condição de entrega total do jogador ao jogo, evidenciando a seriedade própria do jogo, e a certeza de que o jogador está sempre dando o máximo de si para a realização do jogo.

${ }^{2} \mathrm{O}$ termo 'ontologia' é usado aqui, reconhecendo a existência de divergência entre escolas filosóficas (MORA, 2001; CASTRO, 2008), para designar o caráter primário (essência) do fenômeno jogo no que tange aos jogos esportivos coletivos (LEONARDO; SCAGLIA; REVERDITO, 2009). Nessa direção estamos dizendo que os jogos esportivos coletivos, enquanto aquilo que é em si (último e irredutível), ou seja, é jogo.

${ }^{3} \mathrm{O}$ jogo é um fenômeno polissêmico (SCAGLIA, 2003; REVERDITO, 2011), sendo objeto de estudo em diferentes áreas do conhecimento como podemos destacar em relação aos autores citados (sociologia, pedagogia, filosofia, matemática, psicologia), trazendo contribuições significavas, tanto sobre uma compreensão ampla (transdisciplinar) do fenômeno, como irredutível no plano das fronteiras disciplinares.
} 
2003). E é justamente o desejo de jogar que irá garantir que o ambiente de jogo também seja ambiente de trabalho ${ }^{4}$, potencializando o que estamos chamando de ambiente de aprendizagem. Assim, diferente das concepções tradicionais de ensino, é o desejo de ao jogo se entregar que irá sustentar um ambiente de aprendizagem.

$\mathrm{Na}$ medida em que o jogador está em estado de jogo (se entregou ao jogo) ele irá mobilizar os recursos (competências e habilidades) disponíveis para jogar cada vez melhor (obter êxito). Por exemplo, a natureza da atividade do jogo exige do jogador seriedade, caso contrário deixa de ser jogo.

A seriedade caracteriza a maneira de jogar, conforme abordado por Caillois (1990) em sua obra 'os jogos e os homens', hierarquizadas em dois polos antagônicos. Caillois classifica a maneira de jogar em paidia e ludus. A paidia (turbulência) emana na forma de impulso para o jogo, ou seja, na sua manifestação mais simples, em que ocorre o predomino da diversão, improviso, agitação imediata, excessiva liberdade, marcada por impulso para dificuldades gratuitas e necessidade de agitação. O ludus (regras) tem a função principal de absorver ou disciplinar a paidia, prevalecendo a subordinação às regras e convenções - intenção civilizadora, marcada por valores morais e intelectuais (REVERDITO, 2011).

Em uma dimensão de verticalidade, a paidia é decrescente e o ludus crescente. Porém, isso não significa que a paidia é eliminada em relação ao ludus. Justamente a permanência da paidia que garante a liberdade primeira (repouso, distração, fantasia) de expressão, origem e a existência do jogo na forma mais complexa e organizada, ou seja, enquanto ludus. Nesse caso, inexiste a divisão entre jogo e trabalho. E, justamente, na congruência entre jogo (natureza da

\footnotetext{
${ }^{4}$ Freinet (1998) se opõe à ideia de jogo (livre e funcional) como substituto do trabalho, ou de descanso desse, ou seja, não será somente pelo jogo que a criança alcançará a satisfação de todas as suas necessidades essenciais, muito menos as realizará por intermédio do trabalho, se este for concebido de forma imposta e arbitrária. Aí está, aliás, a tarefa essencial da pedagogia: criar uma atmosfera de trabalho produtivo e formativo, e, ao mesmo tempo, prever e preparar as técnicas que tornam esse trabalho acessível, ou seja, um ambiente em que o jogo guarde as suas características essenciais e concomitantemente com a possibilidade de satisfação das necessidades de aprendizagem, nesse estudo, ambiente de aprendizagem dos jogos esportivos coletivos.
} 
atividade) e trabalho (busca pelo êxito do jogo), se garantirá um ambiente de aprendizagem significativo (desejo de jogar melhor).

Assim, em uma metodologia que explore conteúdos por meio de uma situação de jogo na aula/treino, exigirá do professor/técnico o cuidado didático na garantia de um ambiente de jogo, em que os planos pedagógicos (planejamento, objetivos, conteúdos) sejam orientados pela natureza do jogo. Porém, isso não significa que é deixar jogar (jogo pelo jogo). Mas garantir um ambiente de aprendizagem em que os procedimentos e objetivos pedagógicos sejam alcançados na medida em que o jogador mobiliza suas competências e habilidades (ato de jogar) a fim de elucidar a lógica do jogo (jogar melhor/obter êxito).

Desse modo, o jogo oferece a estrutura para a ação (BATESON, 1999; REVERDITO, 2011). Na convergência do impulso lúdico (desejo de se entregar ao jogo) com a matriz abstrata, o jogo é uma ação que está a realizar-se (intenção). O sentido do jogo está na realização da ação (êxito), limitado pela sua natureza como atividade e naquilo que satisfaz ao jogador.

Portanto, entendemos cada manifestação de jogo esportivo coletivo como uma unidade complexa, respeitando sua natureza essencial que se evidencia no ato de jogar. A ação de jogar, carregada de intencionalidade, desejo e tendo por meta elucidar a lógica do jogo, ratifica o ambiente de jogo, gerando o estado de jogo.

Por sua vez, a aspiração de ensinar de forma organizada e deliberada confirma o ambiente de aprendizagem. $\mathrm{Na}$ inter-relação desses ambientes conjeturamos um caminho metodológico para o ensino dos jogos esportivos coletivos, no mesmo instante em que podemos vislumbrar parâmetros para construção de currículos de formação.

Contudo, para pensarmos em currículo de formação para o processo de ensino dos jogos esportivos coletivos, que respeite os ambientes de jogo e aprendizagem, no desencadear de uma metodologia coerente que privilegia o jogo, devemos compreender suas competências essenciais e, principalmente como elas se 
manifestam em meio à lógica de seu processo organizacional sistêmico, delimitando assim, os objetivos deste artigo descritivopropositivo.

\section{As COMPETÊNCIAS ESSENCIASS NO ENSINO DOS JOGOS ESPORTIVOS COLETIVOS}

Todo processo de ensino e aprendizagem orientado, pressupõe um planejamento dos conteúdos - defendemos que se desenvolva de forma espiral ascendente -, observando todas as dimensões que cercam essa atividade em função de um objetivo pretendido, principalmente acerca daquilo que será ensinado, imbricando com o modo que será ensinado, associando-se aos porquês do ensino, a quem se ensina, em determinado contexto social e cultural. $\mathrm{O}$ currículo, assim, deve refletir o perfil do egresso desejado (GIMENO SACRISTÁN, 2000).

No ensino dos diferentes jogos esportivos coletivos o problema já começa por não ser uma prática recorrente a sistematização de currículos (REVERDITO; SCAGLIA; PAES, 2009). E quando feito é baseado na simplificação e descontextualização das partes do jogo: fundamentos, gestos técnicos, táticas (como sinônimo de sistema/ esquema de jogo) e condicionantes físico-motoras. Nessa lógica, se espera que ao aprender (especializar) as partes o jogador transfira as ações condicionadas para o jogo contextual.

Para início de reflexão sobre currículos de formação em jogos esportivos coletivos, negando a abordagem tradicional de ensino, que se vale de uma metodologia tecnicista, e de modo a subsidiar a construção de planejamentos que permitam a gestão do processo e certa condição de direcionamento para se atingir o perfil do egresso desejado, optamos, tendo por referência Scaglia et al. (2011), em ter como ponto de partida as competências essenciais presentes em todos os jogos esportivos coletivos.

As competências essenciais são definidas na congruência do conflito de objetivos inerentes ao jogo e da capacidade do jogador 
para elucidar a lógica do jogo, configurando uma circunstância a qual demanda: estruturação do espaço, comunicação da ação e a relação com a bola (ou implemento). Estas foram nominalmente cunhadas por Garganta (1995), porém não foram pensadas a partir do conceito de competência, mas como características que parametrizam os níveis de jogo ao longo do processo.

Sem necessariamente negar as proposições pertinentes de Garganta (1995), porém embasados nas proposições de Macedo (2005a, 2005b) e Gimeno Sacristán et. al. (2010), o conceito de competência está conectada ao poder fazer. Logo, a partir dessa concepção, ao se falar em competências essenciais para qualquer jogo esportivo coletivo, estamos afirmando que todos são capazes de jogar em algum nível, variando-se apenas o tempo de experiência e a diversidade imbricada dos esquemas de ação (PIAGET, 1976, 1978; GARCIA, 2002), no domínio das habilidades requeridas pela lógica do jogo.

As habilidades, que são mais do que apenas motoras, dizem respeito ao saber fazer (MACEDO, 2005a, 2005b). No jogo, consiste em saber fazer cada vez melhor o que se pode fazer no jogo, resumindo-se em estruturar-se no espaço coletivo, confluindo ações individuais com as coletivas, em relação ao posicionamento dos adversários e a estratégia preestabelecida coletivamente, configurando-se as circunstâncias contextuais do jogo; estas devem ser lidas pelos jogadores à medida que se ampliam suas respectivas habilidades de interpretação da lógica do jogo, aliada ao seu amadurecimento cognitivo e ampliação contextualizada de seus esquemas de ação, comunicando-se por meio de suas ações com os demais jogadores; além de, ao mesmo tempo, manter uma adequada e eficiente relação com a bola (ou implemento), de modo a conseguir executar as ações motrizes requeridas, sempre com o objetivo de ganhar o ponto.

Podemos ilustrar estas conjeturas, dizendo que estruturar o espaço num mini-campo de futebol é relativamente fácil para uma 
criança de 10 anos. Já um campo oficial requer muita habilidade dos jogadores que, transitando da iniciação à especialização, enfrentam o problema de dominar o espaço de um campo oficial de futebol. $\mathrm{Ou}$ então, não basta manter boa relação individual com a bola, é preciso aprender a ler o jogo. E desse modo, aprender a se comunicar em meio à ação, considerando a relação com os companheiros e adversários.

Quando autores como Garganta (1995), Scaglia (2011), Leonardo, Scaglia e Reverdito (2009) advertem sobre a necessidade de se comunicar no jogo, obviamente não estão dizendo que os jogadores devem conversar durante as ações do jogo. Comunicação na ação é uma metacomunicação. É uma comunicação corporal, que acontece à medida que os jogadores aprendem a linguagem do jogo. Aprendem a se comunicar no jogo, por meio de um posicionamento individual, de grupo e coletivo, adequado frente às situações do jogo.

A linguagem do jogo é uma analogia sobre a necessidade de se entender a lógica do jogo, interpretá-la à luz das circunstâncias. Cada jogo, por ser único, irredutível, casual e por natureza ontológica, tendendo ao caos, apresenta uma lógica particular (FREIRE, 2002; SCAGLIA, 2005). Logo, aprender a jogar pressupõe aprender a se comunicar, compreendendo a lógica interna de cada jogo, a partir interpretação de seu padrão de organização ${ }^{5}$, em meio ao seu processo organizacional sistêmico ${ }^{6}$ (SCAGLIA, 2011).

Já a relação com a bola (ou implemento), a terceira competência essencial, não pode se resumir em adestramento técnico. Ao longo do processo, como já salientamos, as ações táticas (motivos de se fazer) devem determinar os gestos técnicos (como se fazer), como já advertia Garganta (1995). E estas, nos jogos coletivos, devem ser

\footnotetext{
${ }^{5}$ Padrão de organização: todos os jogos desportivos coletivos apresentam quatro estruturas sistêmicas padrão (condições externas, regras, jogadores e seus esquemas motrizes) que, ao interagirem de maneira complexa, produzirão emergências - na forma de condutas motoras -, fazendo com que, dessa forma, o jogo aconteça.

${ }^{6}$ Processo organizacional sistêmico: neste texto é considerado como o processo dinâmico e irreversível que acontece no interior das unidades complexas (jogos), quando da interação entre as estruturas sistêmicas, visando organizá-las.
} 
sempre pensadas em sua perspectiva aberta (GRAÇA, 1995), ou seja, desenvolver habilidades em contextos de jogo, em que a imprevisibilidade esteja presente, sendo essa uma das principais características dos jogos esportivos coletivos.

Ainda, de modo a complementar nossa reflexão, alinhada ao esforço de se esboçar o embrião de proposta de sistematização do processo de ensino dos jogos esportivos coletivos, para que o planejamento forneça estrutura coerente para o desenvolvimento de uma metodologia que privilegie as competências essenciais, em meio ao jogo e suas peculiaridades - como o ambiente de jogo -, devemos ordenar as competências essenciais, fazendo com que elas sejam enfatizadas de diferentes modos ao longo do processo de ensino e aperfeiçoamento. Por isso propomos organizá-las em competências essenciais gerais, específicas e contextuais.

As competências essenciais gerais são as manifestações comuns das competências que podem ser encontrada em todos os jogos coletivos. Ou seja, a partir dos estudos, de Bayer (1994), Griffin, Micthell e Oslin (1997), Teodorescu (2003), dentre outros, assumese os conceitos relativos aos princípios comuns presentes em todos os jogos coletivos, os quais são passíveis de transferência de um jogo coletivo para outros devido as suas exigências semelhantes, dando azo ao surgimento da idéia de família dos jogos (LEONARDO; SCAGLIA; REVERDITO, 2009; SCAGLIA, 2011). Ou seja, a partir das teorias sistêmicas/complexas (MORIN, 2001, 2002, 2006) e da concepção de que cada jogo é um sistema complexo (SCAGLIA, 2005, 2011; SCAGLIA; REVERDITO, 2011), pode-se dizer que todo sistema apresenta duas tendências opostas, porém complementares; uma tendência integrativa e outra auto-afirmativa. Uma que o une ao ecossistema maior, e outra que o individualiza, engendrando sua identidade particular.

Já as competências específicas são as manifestações específicas das competências essenciais em decorrência das especificidades requeridas por cada jogo coletivo. Assim, as competências específicas, diferentemente das gerais, que partem 
das semelhanças entre os jogos, elas se preocupam com as diferenças. Dessa vez, das duas tendências de um sistema, neste caso, privilegiam-se as auto-afirmativas.

Por fim, as competências contextuais são as manifestações das competências essenciais em meio às competições regulamentadas do esporte. Assim, as competências essenciais contextuais estão conectadas às competições formais, que também devem ser entendidas como conteúdos a serem ensinados ao longo de todo o processo de ensino-aprendizagem-treinamento, como salientam Reverdito, Scaglia e Montagner (2013), e nunca como avaliação do trabalho desenvolvido pelo professor.

Contudo, as competências essenciais desenvolvidas sempre na forma de jogo, de diferentes modos ao longo do processo de iniciação e aperfeiçoamento dos jogos esportes coletivos, engendrando o que o Freire (2003) indiretamente chamou de Periodização de Jogo (LEONARDO; SCAGLIA; REVERDITO, 2009), devem respeitar e ser direcionadas pela lógica do jogo, ou seja, por sua referência funcional.

\section{A LÓGICA DO JOGO E O PROCESSO ORGANIZACIONAL SISTÊMICO DOS JOGOS ESPORTIVOS COLETIVOS}

Conforme destacam Garganta (1995) e Reverdito e Scaglia (2007, 2009) compreender a lógica do jogo passa a ser um ponto de grande importância para se consubstanciar um método que privilegia as ações táticas (não em detrimento aos gestos técnicos), que emergem em meio às exigências do jogo, no desenvolvimento das competências essenciais.

A partir da clássica obra de Copi (1978), a lógica está relacionada à ciência das leis do pensamento, ou melhor, o conhecimento sobre as leis do raciocínio. Destarte a lógica trata do modo que se encadeia o raciocínio, justificando as decisões em decorrência de fatos básicos.

Desse modo, pensar a lógica do jogo (referência funcional), seu encadeamento circunstancial, será facilitado a partir do 
entendimento do processo organizacional sistêmico dos jogos (SCAGLIA, 2003). Segundo Scaglia (2003, 2005, 2011), há um padrão organizacional no interior da família dos Jogos Esportivos Coletivos. Esse padrão organizacional não se refere a uma possível "camisa de força" ou modelo estereotipado de padronização, próprio dos sistemas mecânicos fechados. O padrão organizacional a que se reporta advém das ideias de Humberto Maturana e Francisco Varela (1997, 2001), dentre outros pensadores que sustentaram pressupostos sistêmicos como Ludwig Von Bertalanffy (2008) e Gregory Bateson (1999).

Esses autores, dentre outros com pensamentos similares e já destacados neste artigo, elaboraram a ideia de padrão organizacional, utilizando-o para explicar a Autopoiesi (autorregulação), termo que se vale Maturana e Varella $(1997,2001)$ para atribuir significado à autoprodução, caracterizando o sistema como autônomo, ou seja, dinâmico o suficiente para sua autogestão.

Segundo Maturana e Varela $(2001,1997)$, o padrão organizacional sistêmico do ser vivo, estabelecido por meio das interações de suas estruturas, geram componentes novos, fazendo dos seres vivos máquinas autopoiéticas. Para esses autores uma máquina autopiética é uma máquina organizada, como um sistema de processos de produção de componentes concatenados de tal maneira que se produzem por meio de processos contínuos de interações e transformações.

Nesta perspectiva, o padrão organizacional se configura nas relações que determinam as características essenciais de um sistema qualquer. Em outras palavras, certas relações devem estar presentes para que algo seja reconhecido como uma cadeira, uma bicicleta, um jogo de rebatida, handebol ou de futebol. A dinâmica de qualquer sistema pode ser explicada mostrando as relações entre suas partes e as regularidades de suas interações, de modo a fazer com que sua organização se torne evidente, como adverte Maturana e Varela (2001, 1997). 
Assim, as estruturas de um sistema incorporam certo padrão organizacional, de modo que suas interações irão produzir componentes (emergências) continuamente diferentes, porém esse diferente não tende a descaracterizar o sistema.

O padrão organizacional dos jogos esportivos coletivos é considerado um processo dinâmico e irreversível, de espiral crescente, que acontece no interior das unidades complexas (jogos), por meio da interação entre as estruturas sistêmicas (condições externas, regras, jogadores e seus esquemas motrizes), visando organizá-las (SCAGLIA, 2005, 2011). O sistema caótico que é o jogo necessita de constantes organizações, perspectivando trazer ordem ao sistema, porém no jogo - por sua tendência ao caos -, sempre que se estabelece uma ordem (solução a um problema), concomitantemente, é desencadeada uma nova desordem.

Portanto, o jogo entendido como sistema é dotado de um princípio organizador, sendo este princípio evidenciado em meio a uma cadeia de acontecimentos cíclicos, que se repetem sempre em níveis superiores, elevando a complexidade do sistema (produzindo diversidade). Esse princípio leva os jogadores a novos patamares de conhecimento à medida que constroem e testam suas soluções (respostas). Pode-se dizer então que a organização gera ao mesmo tempo transformação e formação. A organização forma um todo a partir da transformação de seus elementos, ou seja, o padrão organizacional evidencia o processo de organização, o qual dá forma, no espaço e no tempo, a uma realidade nova (SCAGLIA, 2005, 2011).

\section{REFERÊNCIAS À LÓGICA DO JOGO NOS JOGOS ESPORTIVOS COLETI- VOS: DIRECIONANDO O PLANEJAMENTO E A METODOLOGIA A PARTIR DE MATRIZES DE JOGOS}

Com base nas discussões sobre a lógica do jogo e o processo organizacional sistêmico dos jogos esportivos coletivos, torna-se importante conhecer quais são as referências contidas no jogo 
esportivo coletivo que são responsáveis por orientar o desenvolvimento do jogo para o cumprimento de sua lógica.

Pautados nos estudos de Bayer (1994), a lógica do jogo emana da interação entre as referências estruturais e funcionais (Figura 1), em decorrência do conflito de objetivos inerentes à circunstância do jogo. As referências estruturais consistem nos elementos formais que compõem o jogo: companheiros, adversários, bola/implemento, alvo, espaço e regras. Já as referências funcionais são definidas sobre duas dimensões, orientadas pela posse ou não da bola: os princípios operacionais e as regras de ação.

Pensando no cumprimento da Lógica do Jogo, observa-se que marcar pontos e não sofrer pontos é o princípio que deve reger toda e qualquer ação de um jogador que participa do determinado jogo.

Dessa forma, observa-se que o elemento bola (ou o implemento do jogo) passa a ser um importante referencial para que uma equipe possa atingir o principal objetivo do jogo pois, somente estando com a bola é que existe a chance de se marcar um ponto e ao mesmo tempo, diminuir as possibilidades de sofrer um ponto (BAYER, 1994). Porém, ter a bola não garante a vantagem no placar pois, mesmo que uma equipe possua a posse de bola em $100 \%$ da partida, ela terá deixado de arriscar a perda da posse da bola para tentar marcar o ponto. 
Figura 1 - Relação entre as referências que orientam o cumprimento da lógica do jogo

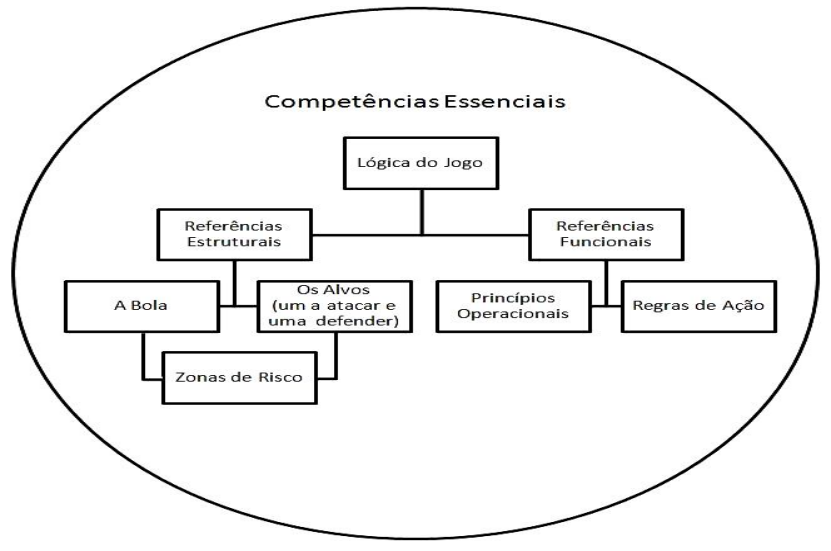

Fonte: SCAGLIA et al., 2011.

Além do elemento bola, para que um ponto seja conquistado existem nos jogos alvos a serem atingidos. Ao analisar os jogos esportivos coletivos de uma maneira ampla, existe sempre um alvo a atacar e um alvo a defender que passam a ser outras importantes referências do jogo, como adverte Bayer (1994), afinal, como discutido anteriormente, não basta ter a bola para que se cumpra a lógica. Torna-se necessária a tentativa de atingir o alvo adversário e ao mesmo tempo afastar a bola das proximidades do próprio alvo.

A partir da relação entre as forças do jogo que impelem e repelem a bola em direção aos dois alvos do jogo, surge também a ideia de zona de risco como uma importante referência para o cumprimento da lógica do jogo. Existe zonas que são perigosas para uma equipe manter a posse de bola, em detrimento da proximidade de seu próprio alvo, mas que podem ser identicamente perigosas para a equipe adversária quando existe a proximidade da bola do alvo adversário.

A partir dessas três referências estruturais (a bola, os alvos e as zonas e risco) pode-se manipular jogos de forma a aproximá-los mais da lógica do jogo esportivo coletivo que se pretende ensinar ou, do mesmo modo, afastá-lo do cumprimento da respectiva lógica do 
jogo. Um exemplo de aproximação é desenvolver jogos cujas três referências estejam presentes. A presença da bola, de um alvo a atacar e um alvo a defender em um espaço de campo delimitado, criando assim zonas de maior ou menor perigo, tornará o respectivo jogo muito próximo à lógica dos jogos esportivos coletivos de invasão.

Porém, um jogo com as mesmas características, que inclua a regra de que vale marcar pontos em qualquer um dos alvos afasta este jogo da lógica dos jogos esportivos coletivos, pois a ideia de zona de perigo e de alvos a defender a atacar transforma-se completamente.

É o caso do jogo de rebatida, analisada por Scaglia (2011) que apesar de possuir semelhanças com o futebol traz em sua estrutura a presença de apenas um gol (logo, uma das equipes não tem porque se preocupar com a sua zona de perigo defensiva), além de valorizar outras formas de marcar pontos, alterando a noção de alvo.

Essa reflexão mostra o quanto à lógica do jogo é um aspecto fundamental para aproximar mais ou menos diferentes tipos de jogo, devendo ser o principal conteúdo que orienta a aplicação de um determinado jogo para o ensino dos jogos esportivos coletivos. Entender se o jogo aplicado em uma aula/treino afasta-se ou aproxima-se da lógica do jogo esportivo coletivo determinado, ou seja, o que se pretende ensinar tem crucial importância para que sua aplicação seja válida ou não, dentro da periodização de um processo de ensino.

A aproximação e o distanciamento referente ao cumprimento da lógica do jogo formal de qualquer jogo esportivo coletivo são determinantes na gestão do processo de formação, pois na iniciação esportiva deve-se valorizar a diversificação de jogos (obviamente não limitando-se as lógicas formais de nenhuma manifestação de jogos esportivos coletivos), esta preocupação gerará diversidade de habilidades, concomitantemente o currículo de formação neste estágio privilegiará o desenvolvimento das competências essenciais gerais. 
Contudo, no decorrer do processo, por exemplo, na fase de especialização, deve-se primar pelo desenvolvimento das competências essenciais específicas e contextuais, explorando jogos que se aproximem da lógica formal do jogo esportivo coletivo que se tem por principal alvo de formação, além da valorização das disputas de competições formais (campeonatos), engendrando especificidade no tocante ao aperfeiçoamento das habilidades requeridas.

Para ilustrar, podemos dizer que em um processo de iniciação no futebol o currículo de formação pode se pautar, por exemplo, nas tradicionais brincadeiras de bola com os pés, mesmo que estas se dispersem muito da lógica formal do jogo de futebol, como a brincadeira de Rebatida, supracitada.

Já, continuar investir nestas brincadeiras, ou mesmo no futsal, ou beach soccer, no processo de especialização passa a se caracterizar um equívoco, pois neste momento, tendo por base a diversidade da iniciação, deve se priorizar jogos que levem em consideração as referências estruturais do futebol, proporcionando a emergência de sua peculiar referência funcional (a lógica formal do futebol).

Assim sendo, a partir do entrelaçamento das referências estruturais e funcionais (lógica do jogo), tecidas juntas às circunstâncias da ação, podemos pensar em matrizes de jogos, as quais visam à materialização da metodologia de ensino pautada no jogo e auxiliam no processo de organização e gestão do currículo de formação, a partir das competências essências gerais, específicas e contextuais. As matrizes de jogos defendidas por nós são: os Jogos Conceituais, os Jogos Conceituais em Ambiente Específico, os Jogos Específicos e os Jogos Contextuais.

Os jogos conceituais são jogos cujas suas referências estruturais (bola, alvos e tamanho do campo, entre outras invariantes) e funcionais (princípios operacionais e regras de ação) não respeitam fielmente a lógica do jogo esportivo coletivo pretendido (ou seja, qualquer manifestação de jogo esportivo coletivo, alvo principal no processo, por exemplo uma escola de futebol, basquetebol, etc.), 
mas sim a manipulação da bola em meio ao desencadeamento do processo organizacional sistêmico. Logo seus conteúdos evidenciados ao longo do processo de organização são diversificados, gerando a manifestação de inúmeras ações conceituais presentes em todos os jogos esportivos coletivos, e não apenas no jogo esportivo coletivo que se almeja ensinar.

Já os jogos conceituais em ambiente específico, são jogos cujas referências estruturais obedecem àquelas do jogo esportivo coletivo pretendido (tamanho do campo, presença de gols a atacar e defender e uma bola em jogo). Neles, conceitos desenvolvidos, conhecidos e reforçados em jogos conceituais serão postos em um ambiente formal, com a finalidade de sua aplicação dentro de estrutura espacial que se assemelhe ao jogo formal. Contudo, ainda há variação em relação ao cumprimento da lógica formal (referência funcional é adaptada segundo o conceito trabalhado), pois o processo de organização sistêmico engendrará ações diferentes da às especificamente exigidas no jogo esportivo coletivo pretendido, para a obtenção das formas de pontuação provenientes das modificações das regras.

Por sua vez, os jogos específicos são jogos cujas referências estruturais e funcionais (lógica do jogo) são mantidas intactas em relação à da lógica do jogo esportivo coletivo pretendido. Assim, assemelham-se a jogos formais (regras oficiais) cujos conceitos desenvolvidos fazem parte de um modelo de jogo (que envolve plataforma de jogo e os meios táticos, entre outros) previamente definido.

Por fim, os jogos contextuais são jogos específicos que guardam relações diretas com a competição formal. Ou seja, devem manterse as referências estruturais exigidas pela competição, como por exemplo, tempo de duração do jogo, tamanho do campo, número de jogadores, substituições etc. Também, na medida do possível, deve se manter as estruturas funcionais (ligadas á lógica do jogo) acrescidas (ou incrementadas) pelos desafios emocionais presentes na competição. Assim, os jogos amistosos e os jogos oficiais, são todos jogos contextuais, e devem ser entendidos como conteúdos 
que necessitam fazer parte do planejamento, pois a competição (na forma de jogos contextuais) é um conteúdo a ser ensinado a todos os alunos, ao longo de todo processo de ensino e aperfeiçoamento dos jogos esportivos coletivos, respeitando as peculiaridades de cada estágio (REVERDITO; SCAGLIA; MONTAGNER, 2013).

\section{Considerações FINAIS}

Na prática, construir uma metodologia para a aprendizagem dos jogos esportivos coletivos que se utilize somente de jogos ao longo de seu processo de ensino mostra-se extremamente coerente, pois estará primando pela produção da diversidade e especificidades de conhecimentos.

O que inicialmente soa paradoxal, se materializa complementar quando pedagogos do esporte, ao compreender o processo organizacional sistêmico, administram os ambientes de aprendizagem em interação com o ambiente de jogo (que se expressa no ato de jogar plenamente, impregnado pelas características naturais do jogo e parametrizado nos polos antagônicos da maneira de jogar - ludus e paidia), gerando o desenvolvimento das competências essenciais (gerais, específicas e contextuais) a partir das diferentes matrizes de jogos.

As matrizes de jogos são manipuláveis para que o desenvolvimento de conceitos (conteúdos), advindos de uma matriz curricular (planejamento/periodização), possam emergir ao mesmo tempo em que contribuem para a formação do perfil do egresso desejado.

Mas é importante salientar que qualquer manifestação de jogo esportivo coletivo, por ser jogo, possui uma lógica intrínseca inexorável (FREIRE, 2002; FREIRE; SCAGLIA, 2003), capaz de possibilitar reconhecível uma determinada modalidade onde quer que seja jogada e por quem quer que a jogue. Dessa forma, reconhecesse que um jogo esportivo coletivo é futebol, ou handebol, ou basquetebol pelo simples fato dele estar sendo jogado. 


\section{ArtigosOrignais}

Por este ponto de vista, por exemplo, aprender qualquer jogo esportivo coletivo não pode se resumir mais ao aprendizado de gestos técnicos estereotipados e descontextualizados de suas razões de ser. As metodologias para o ensino dos jogos esportivos coletivos devem levar em consideração todo um universo de jogos, a família dos jogos (LEONARDO; SCAGLIA; REVERDITO, 2009), pois cada um está contido ao mesmo tempo em todos os outros jogos, e estes estão, por sua vez, relativamente, circunscritos em cada um, mantendo suas idiossincrasias e contextos distintos, formando uma grande teia de conhecimentos. 
Collective sports games teaching: essential competencies and game logic amid the systemic organizational process

Abstract: This descriptive and propositive article has the objective of addressing the teaching process of the collective sports games, assuming that they should be understood in view of the ontological nature of the game, of the organizational process and of the inherent logic of collective games. We propose the teaching process by considering the idea of essential competencies as a reference, which stem from the interaction between structural and functional references, which balance the game logic. Thus we have laid the foundation for the development of a methodology outlined by the game and by the parameters for structuring the syllabus of competencybased training.

Keywords: Collective sports games. Essential competencies. Game logic. Systemic organizational process.

La enseñanza de los juegos deportivos
colectivos: las competencias esenciales y la
lógica del juego en medio del proceso
organizacional sistémico
Resumen: En este artículo descriptivo y propositivo
tenemos por objetivo abordar el proceso de enseñanza
de los juegos deportivos colectivos, partiendo de la
presuposición de que deben ser comprendidos desde
la naturaleza ontológica del juego, del proceso
organizacional y de la lógica inherente a los juegos
colectivos. Proponemos el proceso de enseñanza
teniendo como referencia la concepción de
competencias esenciales, las cuales emanan de la
interacción entre las referencias funcionales y
estructurales, las cuales reglan la lógica del juego.
Así, lanzamos las bases para el desarrollo de una
metodología pautada en el juego y de los parámetros
para la estructuración del currículo de formación
embazado en competencias.
Palabras clave: Juegos deportivos colectivos.
Competencias esenciales. Lógica del juego. Proceso
organizacional sistémico




\section{REFERÊNCIAS}

ALVES, Rubem. Gestação do futuro. Campinas: Papirus, 1987.

BAYER, Claude. O ensino dos desportos coletivos. Lisboa: Dina livros, 1994.

BATESON, Gregory. Steps to an ecology of mind. Chicago: The University of Chicago, 1999.

BERTALANFFY, Ludwing von. Teoria geral dos sistemas: fundamentos, desenvolvimento e aplicações. Petrópolis: Vozes, 2008.

BROUGÈRE, Gilles. O jogo e a educação. Porto Alegre: Artes Médicas, 1998.

CAILLOIS, Roger. O homem e o sagrado. Lisboa: Edições 70, 1988.

CAILLOIS, Roger. Os jogos e os homens. Lisboa: Cotovia, 1990.

CASTRO, Susana de. Ontologia. Rio de Janeiro: Zahar, 2008.

CHATEAU, Jean. O jogo e a criança. São Paulo: Summus,1987.

COPI, Irving Marmer. Introdução à lógica. São Paulo: Mestre Jou, 1978.

EIGEN, Manfred; WINKLER, Ruthild. 0 jogo: as leis naturais que regulam o acaso. Lisboa: Gradiva, 1989.

FREINET, Célestin. A educação do trabalho. São Paulo: Martins Fontes, 1998.

FREIRE, João Batista. Jogo: entre o riso e o choro. Campinas: Autores Associados, 2002.

FREIRE, João. Batista. Pedagogia do futebol. Campinas: Autores Associados, 2003.

FREIRE, João Batista; SCAGLIA, Alcides José. Educação como prática corporal. São Paulo: Scipione, 2003.

GADAMER, Hans-Georg. Verdade e Método I: traços fundamentais de uma hermenêutica filosófica. Petrópolis: Vozes, 2007.

GADAMER, Hans-Georg. Verdade e método II: complementos e índice. Petrópolis: Vozes, 2002.

GARCIA, Rolando. O conhecimento em construção: das formulações de Jean Piaget à teoria de sistemas complexos. Porto Alegre: Artmed, 2002.

GARGANTA, Julio. Para uma Teoria dos Jogos Desportivos Coletivos. In. GRAÇA, A.; OLIVEIRA, J. (Org.). O ensino dos jogos desportivos. Porto: Centro de Estudos dos Jogos Desportivos, 1995. p. 11-25. 
GIMENO SACRISTAN, José. O currículo: uma reflexão sobre a prática. Porto Alegre: Artmed, 2000.

GIMENO SACRISTAN, José et. al. Educar por competências. Porto Alegre: Artmed, 2010.

GRAÇA, Amândio. Os comos e os quandos no ensino dos jogos. In: GRAÇA, A.; OLIVEIRA, J. (Org.) O ensino dos jogos desportivos. Porto: Faculdade de Ciências do Desporto e da Educação Física, Universidade do Porto, 1995. p. 27-34.

GRIFFIN, Linda; MITCHELL, Stephen; OSLIN, Judy. Teaching sport concepts and skill: a tactical games approach. Champaing: Human Kinetics, 1997.

HUIZINGA, Johan. Homo ludens: o jogo como elemento da cultura. São Paulo: Perspectiva, 1999.

KISHIMOTO, Tizuko Morchida. O brincar e suas teorias. São Paulo: Pioneira, 2002.

LEONARDO, Lucas; SCAGLIA, Alcides José; REVERDITO, Riller Silva. O ensino dos esportes coletivos: metodologia pautada na família dos jogos. Motriz, Rio Claro, v. 15, n. 2, p. 236-246, 2009. Disponível em: <http://www.periodicos. rc.biblioteca.unesp.br/index.php/motriz/article/view/2177/2285>. Acesso em: 8 set. 2012.

MACEDO, Lino. Competências e habilidades: elementos para uma reflexão pedagógica. In: J. S. MORAES. (Org.). Exame Nacional do Ensino Médio (ENEM): fundamentação teórico-metodológica. Brasília: O Instituto (INEP/MEC), 2005a. p. 13-28.

MACEDO, Lino. Ensaios pedagógicos. Porto Alegre: Artmed, 2005b.

MARCELLINO, Nelson Carvalho. Pedagogia da animação. Campinas: Papirus, 1989.

MATURANA, Humberto; VARELA, Francisco. A árvore do conhecimento: as bases biológicas da compreensão humana. São Paulo: Palas Athenas, 2001.

MATURANA, Humberto; VARELA, Francisco. De máquinas e seres vivos: autopoiese - a organização do vivo. Porto Alegre: Artmed, 1997.

MORA, José Ferrater. Dicionário de filosofia. São Paulo: Martins Fontes, 2001. MORIN, Edgar. Introdução ao pensamento complexo. Porto Alegre: Sulina, 2006.

MORIN, Edgar. O método I: a natureza da natureza. Porto Alegre: Sulina, 2002.

MORIN, Edgar. O método II: a vida da vida. Porto Alegre: Sulina, 2001.

PIAGET, Jean. Fazer e compreender. São Paulo: Melhoramentos, 1978. 
PIAGET, Jean. A equilibração das estruturas cognitivas. Rio de Janeiro: Zahar, 1976.

RETONDAR, Jeferson José Moebus. Teoria do jogo. Petrópolis: Vozes, 2007.

REVERDITO, Riller Silva. Jogo e desenvolvimento: estudo com crianças de 05 e 06 anos em uma escola privada de Hortolândia-SP. 2011. 215 f. Dissertação (Mestrado Educação Física) - Faculdade de Ciências da Saúde, Universidade Metodista de Piracicaba, Piracicaba, 2011.

REVERDITO, Riller Silva; SCAGLIA, Alcides José. A gestão do processo organizacional do jogo: uma proposta metodológica para o ensino dos jogos coletivos. Motriz, Rio Claro, v. 13, n. 1, p. 51-00, 2007. Disponível em: <http:// www.periodicos.rc.biblioteca.unesp.br/index.php/motriz/article/view/256/742>. Acesso em: 10 mar. 2013.

REVERDITO, Riller Silva; SCAGLIA, Alcides José. Pedagogia do esporte: jogos coletivos de invasão. São Paulo: Phorte, 2009.

REVERDITO, Riller Silva; SCAGLIA, Alcides José; MONTAGNER, Paulo Cesar. Pedagogia do esporte: aspectos conceituais da competição e estudos aplicados. São Paulo: Phorte, 2013.

REVERDITO, Riller Silva; SCAGLIA, Alcides José; PAES, Roberto Rodrigues. Pedagogia do esporte: panorama e análise conceitual das principais abordagens. Motriz, Rio Claro, v. 15, n. 3, p. 600-610, 2009. Disponível em: <http:// www.periodicos.rc.biblioteca.unesp.br/index.php/motriz/article/view/2478/2477>. Acesso em: 10 mar. 2013.

SCAGLIA, Alcides José. O futebol e as brincadeiras de bola. São Paulo: Phorte, 2011.

SCAGLIA, Alcides José. 0 futebol e os jogos/brincadeiras de bola com os pés: todos semelhantes, todos diferentes. 2003. $164 \mathrm{f}$. Tese (Doutorado em Educação Física) - Faculdade de Educação Física, Universidade Estadual de Campinas, Campinas, 2003.

SCAGLIA, Alcides José. Jogo: um sistema complexo. In: FREIRE, J. B.; VENÂNCIO, S. O jogo dentro e fora da escola. Campinas: Autores Associados, 2005. p. 3769.

SCAGLIA, Alcides José et al. A organização do processo de ensino em função da lógica do jogo e das competências essenciais para a aprendizagem dos jogos coletivos de invasão. Revista Portuguesa de Ciências do Desporto, Porto, v. 11, supl. 4, p. 89, 2011. 
SCAGLIA, Alcides José; REVERDITO, Riller Silva. O futebol e os jogos/brincadeiras de bola com os pés: todos semelhantes, todos diferentes. Revista Portuguesa de Ciências do Desporto, Porto, v. 11, supl. 4, p. 89-90, 2011.

TEODORESCU, Leon. Problemas de teoria e metodologia nos jogos desportivos. Lisboa: Livros Horizontes, 2003.

Endereço para correspondência:

Faculdade de Ciências Aplicadas da Unicamp - FCA/UNICAMP

A/C. Prof. Dr. Alcides José Scaglia

R. Pedro Zaccaria, 1300 - Caixa Postal 1068 - CEP.: 13484-350

Limeira - São Paulo - Brasil

Recebido em: 19.03.2013

Aprovado em: 23.08.2013

Movimento, Porto Alegre, v. 19, n. 04, p. 227-249, out/dez de 2013. 